\title{
Mental health: a worthwhile goal
}

\author{
Trevor Jackson deputy editor, The BMJ
}

When the United Nations comes to choose its new set of sustainable development goals, it should be sure to include mental health, argue Graham Thornicroft and Vikram Patel in The BMJ this week (doi:10.1136/bmj.g5189). They set out a range of reasons for why the case is compelling. First among these is that "poorer mental health is a precursor to reduced resilience to conflict." Not only that, but conflict is itself a risk factor for adverse mental health, they add, and in the aftermath of war people with mental illness are often accorded the lowest priority. At a time when some of the most seemingly intractable conflicts continue to wreck and destroy lives-in Syria and Iraq, in eastern Ukraine, and across the border between Israel and Gaza-Thornicroft and Patel's call is particularly pertinent.

As doctors from southern Israel and Gaza, Mark Clarfield (doi:10.1136/bmj.g5023) and Izzeldin Abuelaish (doi:10.1136/ bmj.g5106) must surely recognise the importance of Thornicroft and Patel's argument. While Clarfield, an Israeli geriatrician, and Abuelaish, a Palestinian associate professor of global health, come from opposite sides of the political divide, they reflect on the common ground they share through medicine. Clarfield writes: "We must make peace. I will talk to my people. Please: I implore you to talk to yours. Our patients need us to do so. Let us never forgot that we are both doctors." Abuelaish, three of whose children were killed by shellfire in 2009, replies: "We must find a way to stop the bloodshed, and as doctors we have a voice."

If Clarfield and Abuelaish do ever get the peace that they and the world strongly wish for their region, declaring mental health one of the new sustainable development goals might help further. For Thornicroft and Patel argue that improving mental health systems will also "have a decisive role in making cities and human settlements inclusive, safe, resilient, and sustainable, and this is especially important given the global trend towards urbanisation with its associated risk factors for mental illness."

But in order to improve health systems, planners need to estimate future healthcare needs, and this, according to John Appleby's latest Data Briefing (doi:10.1136/bmj.g5184), depends on successful population projections. But these are difficult to get right, he says, and several past projections have greatly underestimated total population numbers. The reason for this, says Appleby, is that it has proved hard to predict how births, deaths, and migration (often a consequence of war) will change. "What is particularly striking is how consistently wrong projections of deaths have been-and all in the same direction, overestimating the number of deaths." In other words, we (in the West at least) are living longer.

Population projections underpin not only estimate of future healthcare needs, as Appleby points out, but also government spending and tax revenues, housing demand, and road, rail, and air transport needs. But where and how we live and travel are also strongly relevant to our health, as Anthony A Laverty and Christopher Millett discuss in their editorial (doi:10.1136/bmj. g5020) on healthier commuting, linked to a research paper that found that those who walked or cycled to work had a lower body mass index and a lower body fat percentage than those using private transport (doi:10.1136/bmj.g4887). Laverty and Millett's message for health professionals is to tell patients to "leave your car at home."

Cite this as: BMJ 2014;349:95249

๑ BMJ Publishing Group Ltd 2014 